\title{
Editorial
}

\section{STAT-HAWKERS at the Joint Statistical Meeting 2012, San Diego, CA}

\author{
Sarjinder Singh and Stan Lipovetsky
}

Sarjinder Singh, Editor-in-Chief of the journal Model Assisted Statistics and Applications (MASA) organized a booth STAT-HAWKERS at the Joint Statistical Meeting (JSM) of the American Statistical Association, during July 28 August 2, 2012, in San Diego, CA. The First International Meeting of the MASA members of the Editorial Board, reviewers, and guests of the journal, in July $31^{\text {st }}$, at the JSM is shown in Picture 1. The meeting was chaired by Stan Lipovetsky, Co-Editor-in-Chief of MASA. The topics of the discussion included how to promote the journal and to increase its citation rate. Professors Igor Mandel and Vladimir Ladyzhets suggested various ways for solving such problems. Reviewers and would be reviewers Jingjing Doris Gao, Hugh Gong, Fang Liu, and Shawn Odumade shared their thoughts on the subject Professor Wenyaw Chan has been organizing a special issue on "Recent developments in statistical methods for medical research".

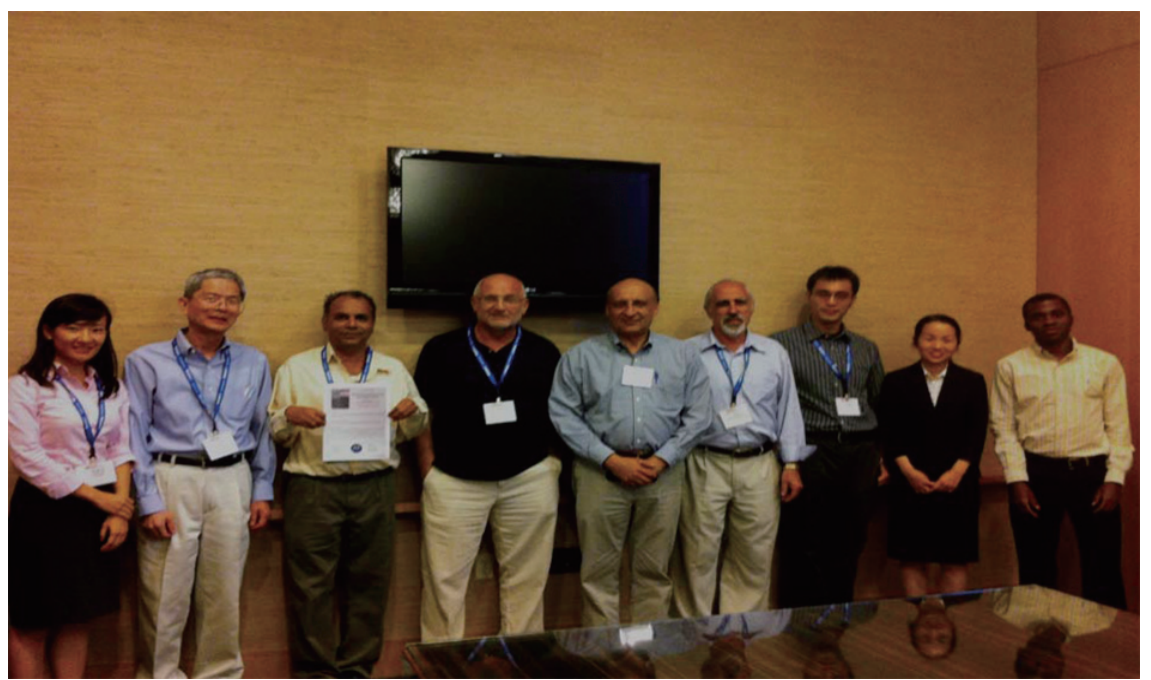

Picture 1. From left to right: Jingjing Doris Gao, Wenyaw Chan, Sarjinder Singh, Igor Mandel, Vladimir Ladyzhets, Stan Lipovetsky, Hugh Gong, Fang Liu, Shawn Odumade.

Below we see several pictures on the activity held in the Booth of STAT-HAWKERS in the Exhibition Hall at JSM. At the booth Sarjinder Singh displayed the 'simple model' and the 'crossed model', proposed by Lee, Sedory and Singh (2011), using a poster. A problem of estimation of proportions of smokers, drinkers and both was considered using the proposed crossed model. He made two decks of cards: Deck-I, a green deck of cards and Deck-II, a pink deck of cards. Two types of cards bearing two different statements made up the green deck of cards: 56 cards with the statement, "I consider myself a smoker" and 24 cards with the statement, "I do not consider myself a drinker." Two types of cards bearing two different statements made up the pink deck of cards: 56 cards with statement, "I consider myself a drinker" and 24 cards with the statement, "I do not consider myself a smoker." During the three days, a total of 136 conference attendees participated in the survey. 


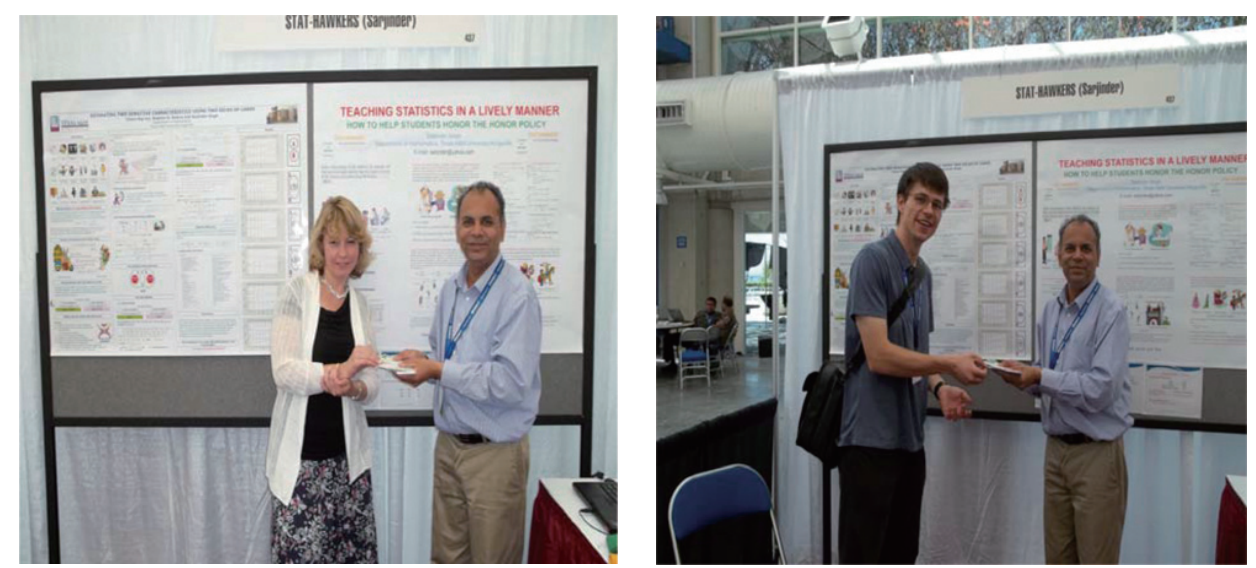

Picture 2: Sarjinder Singh with a deck of cards and conference attendees (left - Dr. Oksana Mokliatchouk, right - another guest) drawing cards from the deck at the booth STAT-HAWKERS at JSM, San Diego, CA.

A two-way classification based on 136 responses is given below:

Table 1

Responses from the survey at San Diego

\begin{tabular}{lcc}
\hline & \multicolumn{2}{c}{ Pink Deck-II } \\
\cline { 2 - 3 } Green Deck-I & Yes & No \\
\hline Yes & 9 & 27 \\
No & 52 & 48 \\
\hline
\end{tabular}

Using the proposed crossed model, the estimate of proportion of smokers is 0.04963 , that of drinkers is 0.23346 and that of smokers as well as drinkers is 0.00285. A senior female participant had mentioned to Sarjinder Singh at the booth while participating in the survey that in San Diego you will not find many smokers because in many restaurants in San Diego the smoking has been strictly prohibited. New findings show that only $4.963 \%$ attendees consider themselves smokers, however $23.346 \%$ attendees consider themselves drinkers, and there is very small overlap of $0.285 \%$ among smokers and drinkers. An estimate of correlation between smoking and drinking attitude is -0.09507 which shows that smoking and drinking have negative relationship. It could be interpreted if smoking is forced to stop in public places then there could be increase in drinking habits and vice versa. The estimate of the relative risk of a drinker to be a smoker is 0.2002 , which means a drinker is 0.2002 times as likely to be a smoker than a non-user of both; whereas the estimate of the relative risk of a smoker to be a drinker is 0.2368 , which means a smoker is 0.2368 times as likely to be a drinker than a non-user of both. Also an estimate of the conditional probability of a drinker to be smoker is 0.01222 and that of smoker to be a drinker is 0.05747 . This study shows that a smoker is more likely to be a drinker than vice versa, and this conclusion is similar to the conclusion based on data collected at the booth STAT-HAWKERS in 2011 at the JSM in Miami Beach, FL.

Many kids who visited at the booth STAT-HAWKERS were given free over a hundred elephants, and were happy receiving them. 


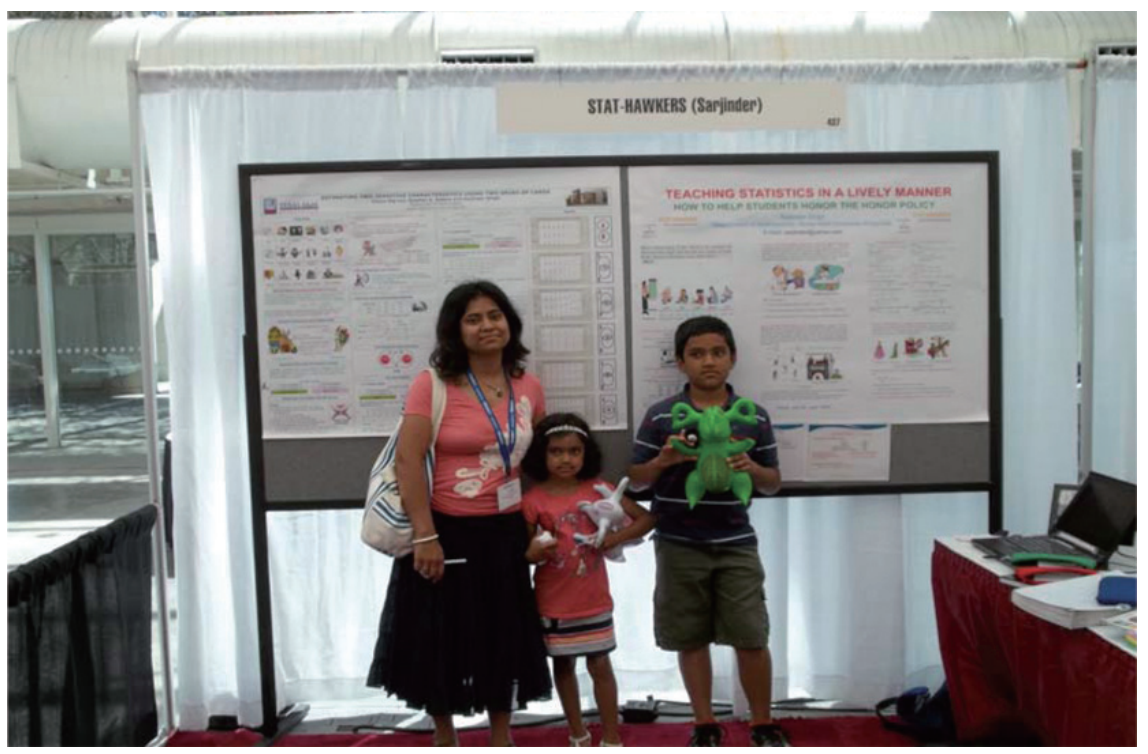

Picture 3. An attendee with kids taking elephants at the booth STAT-HAWKERS at San Diego, CA.

Besides the elephants, over 600 pens with logo of STAT-HAWKERS, 50 hard printed copies of the journal of MASA, and over 200 flyers of the journal were distributed to the visitors. Also recruitment flyers related to the undergraduate and graduate in mathematics programs at Texas A\&M University-Kingsville were distributed. Shawn was always busy to fill the truck with chocolate, and almost 15 big-bags of chocolate snickers were consumed by visitors over three days. It seems proved statistically that people love free snickers. Rasjel van der Holst and Paul Gijsbers from the IOS Press, The Nethlands, helped in promoting the jounal MASA sending materials to the booth.

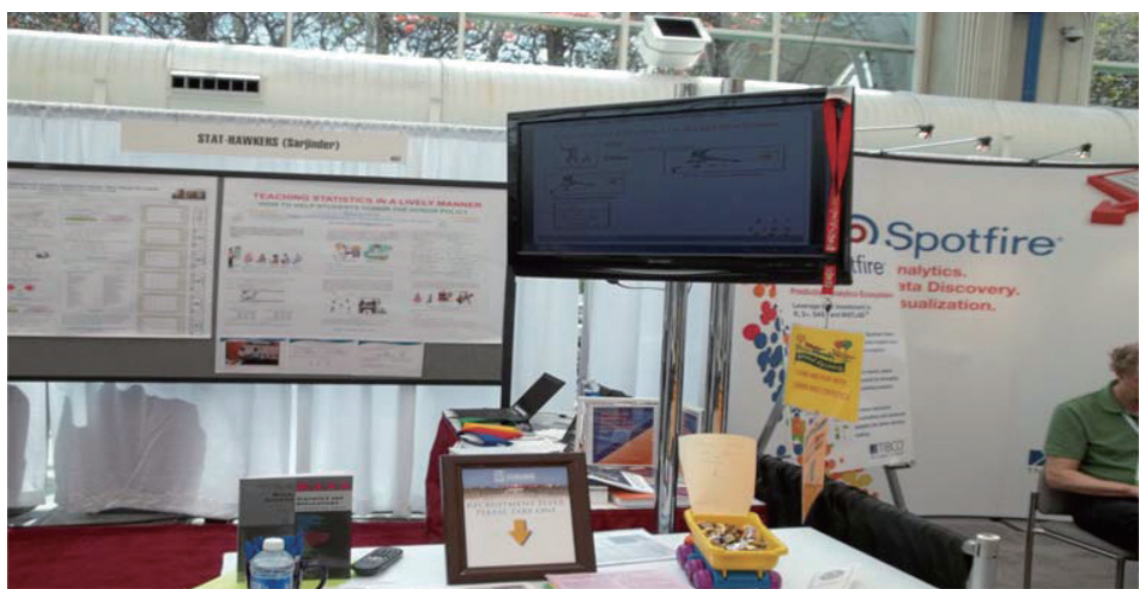

Picture 4. TV and chocolate truck at the booth STAT-HAWKERS.

A TV-set was also rented to display videos related to the MASA journal, and a couple of books were presented there: Thinking Statistically: Elephants Go to School; and Advanced Sampling Theory with Applications: How Michael Selected Amy. During three days at the booth, we were able to make a lot of good friends there. A few friends came to say good-bye at the closing time of the booth. Shawn Odumade was always ready to a volunteer work, offering snacks and love, distributed free elephants and chocolate to others, and was named the hero of social fun at the booth of "STAT-HAWKERS". 


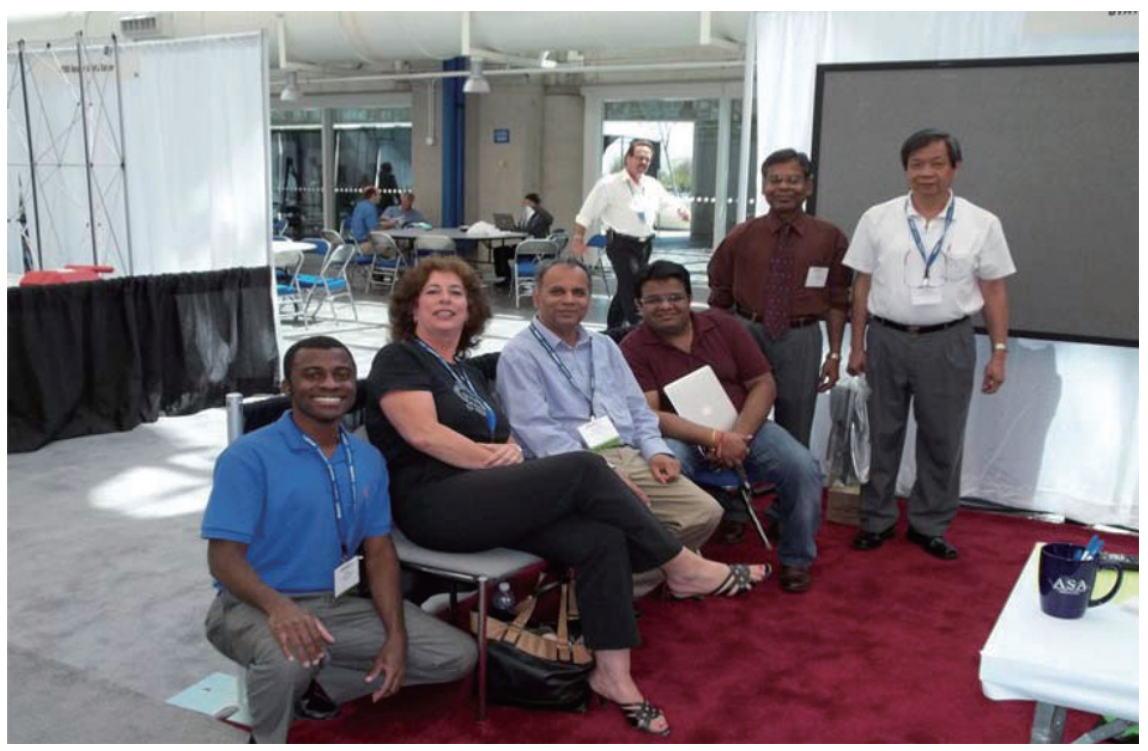

Pictire 5. Friends came to say good bye while closing the booth at San Diego, CA, in the last day of JSM' 12 . 